This item was submitted to Loughborough's Research Repository by the author.

Items in Figshare are protected by copyright, with all rights reserved, unless otherwise indicated.

\title{
A theoretical insight into low-temperature atmospheric-pressure $\mathrm{He}+\mathrm{H} 2$ plasmas
}

PLEASE CITE THE PUBLISHED VERSION

http://dx.doi.org/10.1088/0963-0252/22/5/055016

PUBLISHER

(c) IOP Publishing Ltd

\section{VERSION}

AM (Accepted Manuscript)

\section{PUBLISHER STATEMENT}

This work is made available according to the conditions of the Creative Commons Attribution-NonCommercialNoDerivatives 4.0 International (CC BY-NC-ND 4.0) licence. Full details of this licence are available at: https://creativecommons.org/licenses/by-nc-nd/4.0/

\section{LICENCE}

CC BY-NC-ND 4.0

\section{REPOSITORY RECORD}

Liu, Ding-Xin, Xiao-Hua Wang, Zhi-Zhen Ma, Ming-Zhe Rong, Michael G. Kong, and Felipe Iza. 2019. "A Theoretical Insight into Low-temperature Atmospheric-pressure He+h2 Plasmas". figshare. https://hdl.handle.net/2134/16395. 


\title{
Theoretical insight into low-temperature atmospheric-pressure $\mathrm{He}+\mathrm{H}_{2}$ plasmas
}

Ding-Xin Liu ${ }^{1}$, Felipe $\mathrm{Iza}^{2}$,Xiao-Hua Wang ${ }^{1}$,Zhi-Zhen $\mathrm{Ma}^{1}$, Ming-Zhe Rong ${ }^{1 *}$ and Michael G. Kong ${ }^{1,3}$

${ }^{1}$ State Key Laboratory of Electrical Insulation and Power Equipment, Xi'an Jiaotong University, 710049, P. R. China

${ }^{2}$ School of Electronic, Electrical and Systems Engineering, Loughborough University, LE11 3TU, UK

${ }^{3}$ Frank Reidy Center for Bioelectrics, Department of Electrical \& Computer Engineering, Old Dominion University, Virginia 23508, USA

Email: mzrong@mail.xjtu.edu.cn

\begin{abstract}
$\mathrm{H}_{2}$-containing low-temperature plasmas are used in a wide range of industrial applications. In the past decades, efforts have been made to understand and improve the performance of these plasmas, mainly when operated at low- and medium-pressures. Studies of hydrogen containing plasmas at atmospheric pressure, however, are scarce despite the potential advantage of operation in a vacuum free environment. Here the chemistry of low-temperature atmospheric-pressure $\mathrm{He}+\mathrm{H}_{2}$ plasmas is studied by means of a global model that incorporates 20 species and 168 reactions. It is found that for a fixed average input power the plasma density decreases sharply when the $\mathrm{H}_{2}$ concentration is higher than $\sim 0.2 \%$, whereas the atomic $\mathrm{H}$ density peaks at a $\mathrm{H}_{2}$ concentration of $\sim 2 \%$. Operation at larger hydrogen concentrations leads to lower plasma density and lower $\mathrm{H}$ concentration because at high $\mathrm{H}_{2}$ concentrations significant power is dissipated via vibrational excitation of $\mathrm{H}_{2}$ and there is an increasing presence of negative ions $\left(\mathrm{H}^{-}\right)$. Key plasma species and chemical processes are identified and reduced sets of reactions that capture the main physicochemical processes of the discharge are proposed for use in computationally-demanding models. The actual waveform of the input power is found to affect the average density of electrons, ions and metastables but it has little influence on the density of species requiring low-energy for their formation, such as atomic hydrogen and vibrational states of hydrogen.
\end{abstract}

Keywords: atmospheric pressure glow discharges (APGD); global model; plasma chemistry; hydrogen 


\section{Introduction}

$\mathrm{H}_{2}$-containing low-temperature plasmas display strong reducibility, high diffusivity and slight electronegativity, finding use in a wide range of industrial applications, such as cleaning and passivation of oxide layers ${ }^{[1,2]}$, silicon crystallization $^{[3]}$, polymerization ${ }^{[4,5]}$, etching ${ }^{[6]}$, plasma addressed liquid crystal displays ${ }^{[7]}$ and growth of nanotubes (mixed with $\mathrm{CH}_{4}$ or $\mathrm{CF}_{4}$ as carbon source $)^{[8,9]}$. In the past decades, efforts have been made to understand and improve the performance of these plasmas, mainly when operated at low- and medium-pressures. Studies of hydrogen containing plasmas at atmospheric pressure, however, are scarce despite the potential advantage of operation in a vacuum free environment.

In this paper, low-temperature atmospheric-pressure $\mathrm{He}+\mathrm{H}_{2}$ plasmas are studied by means of a global model. Global models have been widely used to study the chemistry of low-pressure ${ }^{[10-12]}$ and atmospheric-pressure ${ }^{[13-16]}$ plasmas, as they provide a computationally effective way of analysing plasma chemistry and identifying key chemical pathways. Global models of atmosphericpressure $\mathrm{He}+\mathrm{O}_{2}, \mathrm{He}+\mathrm{H}_{2} \mathrm{O}$ and $\mathrm{He}+\mathrm{O}_{2}+\mathrm{H}_{2} \mathrm{O}$ plasmas have been reported in recent years and qualitative agreement have been found between computational results and experimental observations made via optical spectroscopy and mass spectrometry ${ }^{[14-17]}$. The $\mathrm{He}+\mathrm{H}_{2}$ model used in this study incorporates 20 plasma species and 168 chemical reactions, which have been compiled from an extensive literature review.

Results are presented for a wide range of $\mathrm{H}_{2}$ concentrations ( $1 \mathrm{ppm}$ up to $50 \%$ ) and due to their application relevance, special attention is paid to the density and generation mechanisms of $\mathrm{H}$ and $\mathrm{H}^{-}$. Vibrational excitation of $\mathrm{H}_{2}$ is also discussed as significant differences are found when comparing atmospheric-pressure $\mathrm{He}+\mathrm{H}_{2}$ discharge with their low-pressure counterparts. In addition, the power modulation effect on the plasma-induced species is discussed for four input power waveforms.

The manuscript is structured as follows. A description of the global model is given in section 2, and simulation results for a sinusoidal input power are presented in section 3, where density trends, generation/loss mechanism of selected species and power dissipation are discussed as a function of the $\mathrm{H}_{2}$ concentration. Key plasma species and chemical pathways are also identified and reduced sets of reactions and plasma species are proposed for computationally intense models. Finally, in section 4 , the influence of the time variation of the input power on the density of plasma species is discussed. 


\section{Computational model}

Here we consider a global model of a discharge sustained between two parallel-plate circular electrodes with a radius of $1 \mathrm{~cm}$ and a gap between them of $2 \mathrm{~mm}$. The $\mathrm{He}+\mathrm{H}_{2}$ discharge is sustained at atmospheric-pressure and it is excited by an RF source $(13.56 \mathrm{MHz})$ that delivers an average power density of $40 \mathrm{~W} / \mathrm{cm}^{3}$. The neutral gas temperature is assumed to remain at room temperature $(300 \mathrm{~K})$, and the gas flow rate is set to $100 \mathrm{sccm}$. These conditions are the same as the conditions used in similar computational studies of other atmospheric-pressure discharges and they reflect conditions encountered in actual experiments ${ }^{[14-16]}$. The $\mathrm{H}_{2}$ concentration in the feed gas is varied between 1 part per million (ppm) and 50\%, covering a wide range of $\mathrm{He} / \mathrm{H}_{2}$ admixtures relevant for applications.

Global models solve particle and power balance equations and they have been widely used to study the chemistry of low-pressure ${ }^{[12,18]}$ and atmospheric-pressure ${ }^{[13-16]}$ plasmas. They are zero dimensional models that neglect spatial variations by describing the plasma in terms of average quantities. As a result, global models are computational inexpensive and they can easily handle large sets of chemical reactions. Due to these simplifications and the uncertainty in some reaction rates, results of global models typically provide insights into key underlying chemical pathways in a qualitative manner.

The particle balance equation for each plasma species is given by ${ }^{[14]}$ :

$$
\frac{d n_{k}}{d t}=G_{k}+\frac{S}{V}\left(\sum_{i=1, i \neq k}^{N} \alpha_{i, k} \Gamma_{i}-\beta_{k} \Gamma_{k}\right)-\frac{F}{V} n_{k}
$$

where $n_{k}\left[\mathrm{~cm}^{-3}\right]$ is the number density of species $k, G_{k}\left[\mathrm{~cm}^{-3} \mathrm{~s}^{-1}\right]$ the net generation/loss rate of species $k$ due to reactions in the bulk plasma, $N$ the total number of species, $S\left[\mathrm{~cm}^{2}\right]$ the total area of the electrodes, $V\left[\mathrm{~cm}^{3}\right]$ the plasma volume, $\Gamma_{k}\left[\mathrm{~cm}^{-2} \mathrm{~s}^{-1}\right]$ the flux of species $k$ to the electrodes, $\alpha_{i, k}$ the probability of producing species $k$ by a reaction on the electrode from species $i, \beta_{k}$ the surface loss probabilities of species $k$ and $F$ the gas flow rate [sccm]. The first term on the right hand side represents volume processes, the second term the particle gain/loss due to surface reactions on the electrodes, and the third term the loss due to gas flow. Losses of species on the boundaries are dealt with as described in detail in previous works ${ }^{[14]}$. In brief, the negative ions are assumed to be confined by the ambipolar field, i.e. $\Sigma \Gamma_{-}=0$, and the electron loss balances the positive ion flux thereby keeping the plasma quasi-neutral. Although atmospheric-pressure sheath-dominated discharges in which quasi-neutrality does not hold have been reported in the literature, these occur in discharges with a smaller gap than the $2 \mathrm{~mm}$ considered in this study ${ }^{[19,20]}$. Diffusion in the radial 
direction is neglected here since the mean distance travelled by particles during their lifetime is much shorter than the radius of the electrodes ${ }^{[14,21]}$ : for a typical lifetime $(\tau)$ of $1 \mathrm{~ms}$ and a diffusion constant $(D)$ of $1 \mathrm{~cm}^{2} / \mathrm{s}$, the distance travelled in a lifetime is $\sqrt{D \tau}<3 \times 10^{-2} \mathrm{~cm}$ which is much smaller than the electrode radius $(1 \mathrm{~cm})$.

Reaction rates needed to determine the generation/loss of species in the discharge $\left(G_{k}\right)$ depend on the mean electron energy. This is determined by solving the power equation ${ }^{[1,14]}$. Typically, it is assumed that power delivered to the plasma is mainly coupled to electrons although various schemes have been proposed to account also for power dissipation in the sheaths ${ }^{[10-14]}$. Here we follow the approach used in reference [14]. In addition, it is noted that a significant amount of power can also be coupled to ions in the bulk plasma of an atmospheric pressure discharge. The ratio of power coupled to ions in the bulk to the total (electrons + ions) power coupled to the bulk plasma is given by ${ }^{[21]}$ :

$$
r=\frac{\sum_{k} \mu_{i}^{k} n_{i}^{k}}{\mu_{e} n_{e}+\sum_{k} \mu_{i}^{k} n_{i}^{k}}
$$

Where $\mu_{e}\left[\mathrm{~cm}^{2} \mathrm{~V}^{-1} \mathrm{~s}^{-1}\right]$ is the electron mobility, $n_{e}\left[\mathrm{~cm}^{-3}\right]$ the electron density, $\mu_{i}^{k}\left[\mathrm{~cm}^{2} \mathrm{~V}^{-1} \mathrm{~s}^{-1}\right]$ the mobility of ionic species $k$, and $n_{i}^{k}\left[\mathrm{~cm}^{-3}\right]$ the density of ionic species $k$. In electropositive discharges the electron density is comparable to the ion density and due to its larger mobility most of the current in the bulk is carried by electrons and hence most of the power is coupled to the electrons. However, if the discharge becomes electronegative, the electron density will be smaller than the ion density and the ion current in the bulk may not be negligible when compared to the electron current. For a $\mathrm{He}+\mathrm{H}_{2}$ plasma, we can take $\mathrm{H}_{3}{ }^{+}$as a representative ions. Its mobility is $40 \mathrm{~cm}^{2} \mathrm{~V}^{-1} \mathrm{~s}^{-1}$ and that of the electrons is $1056 \mathrm{~cm}^{2} \mathrm{~V}^{-1} \mathrm{~s}^{-1[22,23]}$. Therefore, according to equation 2 even when the density of electrons and ions are equal, $\sim 4 \%$ of the power dissipated in the bulk is coupled to the ions. Taking into consideration the energy coupled to ions in the bulk plasma, the electron power balance equation can be written as:

$$
\frac{d}{d t}\left(\frac{3}{2} n_{e} T_{\text {eff }}\right)=\frac{P_{i n}}{e V}(1-r)-\sum_{i=1}^{N_{r}} \varepsilon_{i} R_{i}-\frac{S_{1}}{V}\left(\varepsilon_{e} \Gamma_{e}+\sum_{j=1}^{N_{p}} \varepsilon_{p} \Gamma_{1 j}\right)
$$

where $e$ is the elementary charge, $T_{\text {eff }}[\mathrm{eV}]$ the effective electron temperature, $P_{i n}[\mathrm{~W}]$ is the input power, $N_{r}$ the number of electron impact reactions, $\varepsilon_{i}[\mathrm{eV}]$ and $R_{i}\left[\mathrm{~cm}^{-3} \mathrm{~s}^{-1}\right]$ the electron energy loss due to the $i$ th electron impact reaction (including electron-neutral momentum transfer collision) and 
the corresponding reaction rate, $\varepsilon_{e}[\mathrm{eV}]$ and $\varepsilon_{p}[\mathrm{eV}]$ the energy lost per electron and ion escaping the plasma across the sheaths. Given the large collisionality of atmospheric-pressure discharges, the electron energy relaxation time is short and the electron temperature is expected to be markedly time-modulated. The actual waveform of the instantaneous power, however, is unknown a priory and for a fixed input voltage it will vary depending on the plasma density and discharge geometry $^{[24]}$. For simplicity, results presented in section 3 assume that the input power varies as $P(t)=\frac{\pi}{2} P_{\text {ave }}|\sin (\omega t)|$, where $P_{\text {ave }}$ is the phase average input power. A discussion on other time variations of the input power can be found in section 4 .

Equation (1) and (3) are integrated using a self-developed MATLAB code that makes use of the built-in stiff ordinary differential equations solver ode $23 s$ to solve for the evolution of the electron temperature and species densities ${ }^{[25]}$. The time resolution is chosen so that the rf modulation is accurately captured and the simulations are run until the relative change in phase-averaged densities between consecutive cycles is less than $10^{-4}$. Further description of the model, the reader is directed to references 11 and 14. The model considers 20 species and 168 reactions that have been identified after an extensive literature review. The species incorporated in the model are listed in table 1, and a list of the reactions can be found in table A1 in the appendix. Vibrationally excited states $\mathrm{H}_{2}(v)$ and Rydberg states $\mathrm{H}_{2}(\mathrm{R})$ are taken into account to investigate their effect on $\mathrm{H}^{-}$formation and power dissipation. $\mathrm{H}_{5}{ }^{+}$and larger cluster ions are not considered in this model due to the lack of reliable data. Reaction rate coefficients are either taken from the literature or calculated from cross section data using Bolsig ${ }^{[26]}$, a Boltzmann solver. In the latter case, look up tables of the reaction rates as a function of the mean electron energy and gas composition are generated and fed to the global model. In a few instances where data was not available educated estimates have been made based on the recommendations given in references 27 and 28. Some cross sections for excited states of $\mathrm{H}_{2}$ have also been estimated by shifting cross sections of the ground state by the threshold energy, as suggested in reference 12 .

Table 1. The 20 species included in the global model

\begin{tabular}{|c|c|c|c|}
\hline Species & Model $^{\mathrm{a}}$ & Species $^{b}$ & Model \\
\hline $\mathrm{He}$ & $\mathrm{S}$ & $\mathrm{He}^{*}$ & $\mathrm{~S}$ \\
\hline $\mathrm{H}_{2}$ & $\mathrm{~S}$ & $\mathrm{He}_{2}{ }^{*}$ & $\mathrm{~S}$ \\
\hline $\mathrm{e}$ & $\mathrm{S}$ & $\mathrm{H}$ & $\mathrm{S}$ \\
\hline $\mathrm{He}^{+}$ & $\mathrm{S} 1$ & $\mathrm{H}(\mathrm{n}=2)$ & \\
\hline
\end{tabular}




$\begin{array}{llll}\mathrm{He}_{2}{ }^{+} & \mathrm{S} 1 & \mathrm{H}(\mathrm{n}=3) & \\ \mathrm{HeH}^{+} & \mathrm{S} 1 & \mathrm{H}_{2}(v=1) & \mathrm{S} \\ \mathrm{H}^{+} & \mathrm{S} & \mathrm{H}_{2}(v=2) & \mathrm{S} \\ \mathrm{H}_{2}^{+} & \mathrm{S} & \mathrm{H}_{2}(v=3) & \mathrm{S} \\ \mathrm{H}_{3}{ }^{+} & \mathrm{S} & \mathrm{H}_{2}\left(v^{\prime \prime}\right) & \mathrm{S} 2 \\ \mathrm{H}^{-} & \mathrm{S} 2 & \mathrm{H}_{2}(\mathrm{R}) & \end{array}$

${ }^{a} \mathrm{~S} 1$ : species relevant only in regime $1\left(\left[\mathrm{H}_{2}\right]<0.5 \%\right)$; $\mathrm{S} 2$ : species relevant only in regime 2 $\left(\left[\mathrm{H}_{2}\right]>0.5 \%\right) ; \mathrm{S}$ : main species in both regime 1 and regime 2

${ }^{b} \mathrm{H}_{2}\left(v\right.$ ') represents vibrational excited states of $\mathrm{H}_{2}(v \geq 4) ; \mathrm{H}_{2}(\mathrm{R})$ represents Rydberg states of $\mathrm{H}_{2}$.

\section{Simulation results and analysis}

\subsection{Density of plasma species as a function of $\mathrm{H}_{2}$ concentration}

The phase-averaged density of charged species in $\mathrm{He}+\mathrm{H}_{2}$ plasmas as a function of $\mathrm{H}_{2}$ concentration is shown in Fig.1. The densities of $\mathrm{He}^{+}$and $\mathrm{H}_{2}^{+}$are very small and they are not shown in the figure. At low $\mathrm{H}_{2}$ concentrations $\left(\left[\mathrm{H}_{2}\right]<10 \mathrm{ppm}\right)$, the dominant ionic species are $\mathrm{He}_{2}{ }^{+}, \mathrm{HeH}^{+}$ and $\mathrm{H}^{+}$, whereas at higher hydrogen concentrations $\mathrm{H}_{3}{ }^{+}$becomes the dominant ion. This trend is similar to that observed in $\mathrm{He}+\mathrm{N}_{2}{ }^{[29]}, \mathrm{He}+\mathrm{O}_{2}{ }^{[14]}, \mathrm{He}+\mathrm{H}_{2} \mathrm{O}^{[15,30]}$ atmospheric-pressure discharges and it can be concluded that unless very high purity He is used $(>99.999 \%)$, cluster ions will be the dominant ionic species in He atmospheric-pressure discharges.

The electron density is found to increase initially with the addition of hydrogen into the discharge, reaching a maximum at $\left[\mathrm{H}_{2}\right] \sim 20 \mathrm{ppm}$. The dependence of the electron density on the hydrogen concentration, however, is fairly weak as long as the hydrogen concentration remains less than $\sim 0.2 \%$. At higher hydrogen concentrations, the electron density decreases rapidly (Fig.1) due to the increasing energy lost in vibrational excitation (see further discussion in section 3.3). It is noted that in experimental studies, a small fraction of $\mathrm{H}_{2}$ around $1 \%$ is often introduced as a means to measure the electron density by Stark broadening of the $\mathrm{H}_{\beta}$ line ${ }^{[31-33]}$. If the electron density of an atmospheric-pressure helium discharge is to be measured, however, introducing less than $0.2 \%$ of hydrogen is recommended in order to minimize the change in electron density caused by the presence of hydrogen.

As shown in Fig.1, the main anion is $\mathrm{H}^{-}$and its density increases with increasing concentration of $\mathrm{H}_{2}$ in the discharge. The ratio $\left[\mathrm{H}^{-}\right] /[\mathrm{e}]$, however is typically $<1$ for the conditions considered in this study and therefore the discharge remains electropositive. The phase-averaged electron temperature 
is also shown in Fig.1. The electron temperature remains fairly constant for hydrogen concentrations of up to $\sim 1 \%$ and then it decreases due to the lower ionization threshold of $\mathrm{H}_{2}$ ( $15.4 \mathrm{eV}$ instead of $24.6 \mathrm{eV}$ required for helium). The variations at low hydrogen concentration $\left(\left[\mathrm{H}_{2}\right]<1 \%\right)$ are attributed to the varying significance of Penning processes.

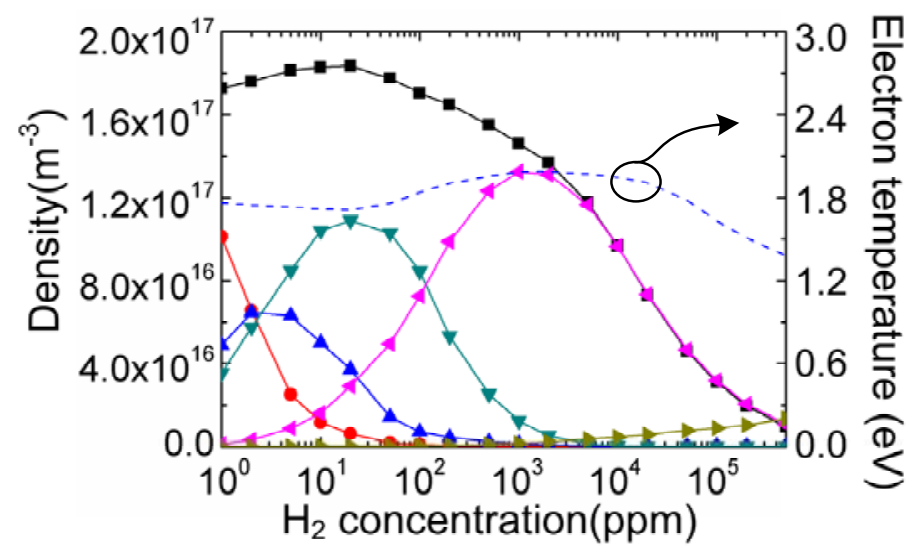

Fig.1 Density of charged species as a function of $\mathrm{H}_{2}$ concentration

$\rightarrow-$ Electron; $\rightarrow-: \mathrm{He}_{2}^{+} ; \rightarrow-\mathrm{HeH}^{+} ; \rightarrow-\mathrm{H}^{+} ;-4: \mathrm{H}_{3}^{+} ; \rightarrow-: 100 \times \mathrm{H}^{-}$; dash line: Electron temperature

Fig. 2 shows the phase-averaged density of the most abundant neutral species as a function of $\mathrm{H}_{2}$ concentration. Species not listed in Fig. 2 have densities smaller than $10^{17} \mathrm{~m}^{-3}$. The densities of helium (atomic and dimer) metastables decrease sharply with increasing $\mathrm{H}_{2}$ concentration, whereas the densities of vibrationally excited $\mathrm{H}_{2}$ increase. At hydrogen concentrations smaller than $1 \%$ $\left(10^{4} \mathrm{ppm}\right), \mathrm{H}$ atoms are the most abundant neutral species (after the ground state background gases). At higher $\mathrm{H}_{2}$ concentrations, however, vibrationally excited $\mathrm{H}_{2}$ becomes more abundant. The density of vibrationally excited states in $\mathrm{He}+\mathrm{H}_{2}$ plasmas is found to be larger than in similar $\mathrm{He}+\mathrm{O}_{2}$ discharges ${ }^{[14]}$ and the implications in terms of plasma chemistry and energy dissipation are discussed in section 3.4. Finally it is noted that the Rydberg states of $\mathrm{H}_{2}$ have a similar trend as the atomic hydrogen, with a maximum density at $\left[\mathrm{H}_{2}\right] \sim 1 \%$ but with a density that is $\sim 9$ orders of magnitude smaller.

Atomic hydrogen is believed to be critical in many applications of hydrogen containing plasmas, such as passivation of oxide surface $\operatorname{layer}^{[} 1^{]}$, silicon crystallization ${ }^{[}{ }^{]}$, etching $\left[6^{[}\right.$and air purification $^{[34]}$. Therefore, an optimum feed gas composition for atmospheric-pressure $\mathrm{He}+\mathrm{H}_{2}$ plasmas would be $\mathrm{He}+2 \% \mathrm{H}_{2}$ as this would maximize the density of atomic H. Furthermore, limiting the concentration of $\mathrm{H}_{2}$ to $2 \%$ would mitigate the risk of flame and/or explosion ${ }^{[35]}$. 


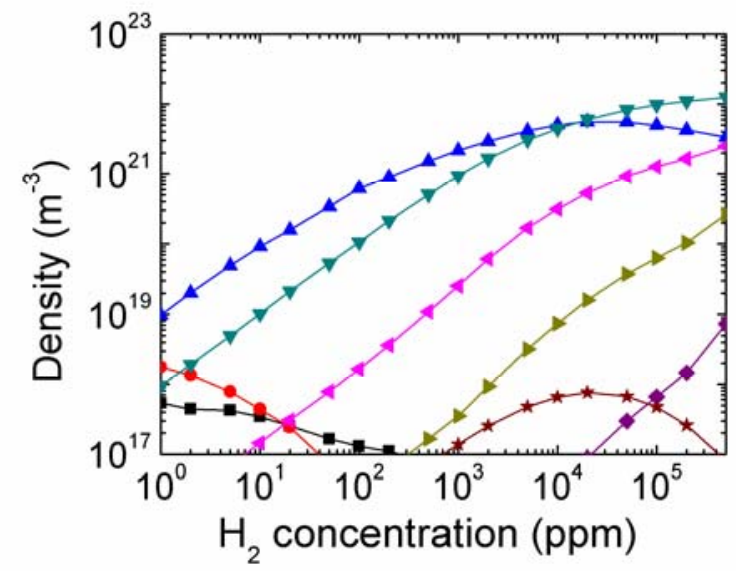

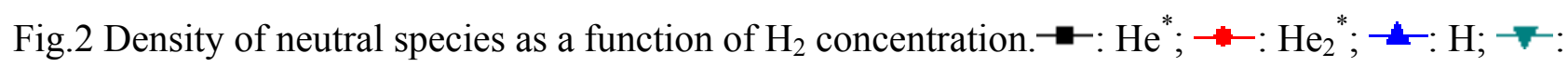

$$
\mathrm{H}_{2}(v=1) ;-\bullet: \mathrm{H}_{2}(v=2) ; \rightarrow: \mathrm{H}_{2}(v=3) ; \multimap-\mathrm{H}_{2}\left(v^{\prime \prime}\right) ; \rightarrow-: 10^{6} \times \mathrm{H}_{2}(\mathrm{R})
$$

\subsection{Generation and loss mechanisms of electrons, $\mathbf{H}^{-}$and $\mathbf{H}$}

As shown in Fig. 3a, electron generation is primarily due to Penning processes and the main electron loss mechanism is the loss to the electrodes (Fig. 3b). This trend is similar to that observed in other helium-based atmospheric-pressure plasmas ${ }^{[14-16,29]}$. The rate of Penning ionization increases with increasing $\mathrm{H}_{2}$ concentration as more $\mathrm{H}_{2}$ becomes available for collisions with metastable helium atoms and dimers, reaching a maximum rate at $\left[\mathrm{H}_{2}\right] \sim 1000 \mathrm{ppm}$. At very high $\mathrm{H}_{2}$ concentration, dissociative attachment (mainly R50: $e+H_{2} \rightarrow H+H^{-}$) and collisional detachment (mainly R73: $\mathrm{H}^{-}+\mathrm{H} \rightarrow \mathrm{H}_{2}+e$ ) become important, resulting in an electron energy loss channel with $\mathrm{H}^{-}$as an intermediate. At this high $\mathrm{H}_{2}$ concentrations $(>5 \%)$, electron impact ionization is more effective than Penning processes.

The non-monotonous trend of the electron impact ionization rate shown in Fig. 3a reflects the variations in electron temperature shown in Fig. 1. At $\left[\mathrm{H}_{2}\right]<20 \mathrm{ppm}$, Penning processes become more efficient with increasing $\mathrm{H}_{2}$ concentration, leading to a reduction in the mean electron energy required to sustain the plasma (Fig. 1) and thereby a decrease in the electron impact ionization rate. The decreasing trend observed at $\mathrm{H}_{2}$ concentrations beyond $1 \%$ is attributed to the lower electron density present in the discharge at high $\mathrm{H}_{2}$ concentration (Fig. 1).

It is noted that dissociative attachment of vibrational excited $\mathrm{H}_{2}(v)$ and $\mathrm{H}_{2}(\mathrm{R})$ play a limited role in the electron density balance (Fig. 3b). This is due to the high collisionality of atmospheric plasmas, which results in rapid collisional quenching of energetic states. As a result, dissociative attachment in atmospheric-pressure $\mathrm{He}+\mathrm{H}_{2}$ plasmas plays a much lower role in the electron balance 
than in low-pressure $\mathrm{H}_{2}$-containing plasmas ${ }^{[36]}$.

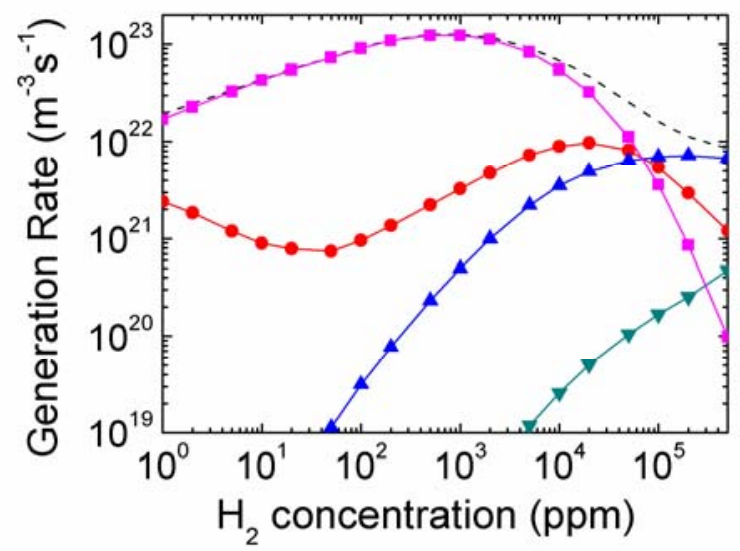

(a)

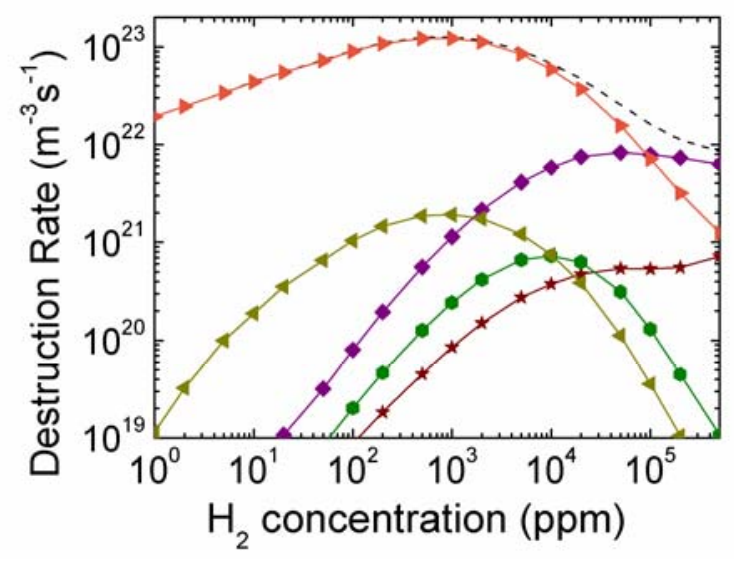

(b)

Fig.3 Processes contributing to (a) generation and (b) loss of electrons.

---: Total rate; $-\rightarrow$ : Electron impacted ionization; $\stackrel{-\leftarrow}{-} H^{-}+H \rightarrow H_{2}+e ;-\boldsymbol{\top}$ : Collisional detachment by $\mathrm{H}_{2}(v)$; - - - Penning ionization; $-\bullet$ : Dissociative attachment of $\mathrm{H}_{2} ;-\star$ :

Dissociative attachment of $\mathrm{H}_{2}(v) ;-$ : Dissociative attachment of $\mathrm{H}_{2}(\mathrm{R}) ;-\square$ : Electron-ion recombination; $\rightarrow$ : Electrode loss

The main production mechanism of $\mathrm{H}^{-}$in hydrogen containing plasmas remains unclear ${ }^{[37,44]}$ and in low-pressure discharges it is normally attributed to the following two processes ${ }^{[36]}$ :

$$
\begin{aligned}
& e+H_{2}(v) \rightarrow H+H^{-} \\
& e+H_{2}(R) \rightarrow H+H^{-}
\end{aligned}
$$

Regarding the dissociative attachment of vibrationally excited $\mathrm{H}_{2}(v)(\mathrm{R} 51-54)$, it is found that the 
process is dominated by the dissociative attachment of high-energy states, i.e. $\mathrm{H}_{2}\left(v^{\prime \prime}\right)$. This agrees with the trend observed in medium-pressure hydrogen discharges ${ }^{[} 7^{]}$. The rate coefficients for reactions R51-55, however, are not well defined and this has contributed to the controversy over the main mechanism leading to $\mathrm{H}^{-}$production. Here we have assumed that the rate of $\mathrm{R} 55$ is $6 \times 10^{-}$ ${ }^{5} \mathrm{~cm}^{3} / \mathrm{s}$, one of the largest values reported in the literature ${ }^{[37]}$, and found that the contribution of Rydberg states is 3 orders of magnitude lower than that of ground state $\mathrm{H}_{2}$. The dissociative attachment of $\mathrm{H}_{2}\left(v^{\prime \prime}\right)$ is also small, even smaller than that of low-energy vibrationally excited $\mathrm{H}_{2}$, i.e. $\mathrm{H}_{2}(\mathrm{v}=1 \sim 3)$ when $\left[\mathrm{H}_{2}\right]<20 \%$. So, the main production mechanism of $\mathrm{H}^{-}$at atmospheric pressure is found to be neither of these mechanisms. Instead, dissociative attachment of ground state $\mathrm{H}_{2}$ (R50: $e+H_{2} \rightarrow H^{-}+H$ ) results in a generation rate of $\mathrm{H}^{-}$that is $\sim 1$ order of magnitude larger than the rest. This is a consequence of the larger collisionality of the discharge that leads to: 1) lower electron mean energy than in low pressure plasmas and therefore lower generation rates of energetic species such as vibrationally excited $\mathrm{H}_{2}\left(v\right.$ ") and Rydberg states $\mathrm{H}_{2}(\mathrm{R})$; and 2) collisional relaxation of energetic excited states. As a result, the density ratios of $\left[\mathrm{H}_{2}\left(v^{\prime \prime}\right)\right]$ and $\left[\mathrm{H}_{2}(\mathrm{R})\right]$ to $\left[\mathrm{H}_{2}\right]$ are much lower in atmospheric-pressure plasmas than in their low-pressure counterparts, and hence R50, instead of R51-54 and/or R55, dominates $\mathrm{H}^{-}$production. Regarding the loss mechanisms for $\mathrm{H}^{-}$(Fig 4b), collisional detachment by $\mathrm{H}_{2}(v)(\mathrm{R} 75-77)$ dominates at low $\mathrm{H}_{2}$ concentrations $\left(\left[\mathrm{H}_{2}\right]<100 \mathrm{ppm}\right)$ and R73: $\mathrm{H}^{-}+\mathrm{H} \rightarrow \mathrm{H}_{2}+e$ becomes the main process at higher $\mathrm{H}_{2}$ concentrations.

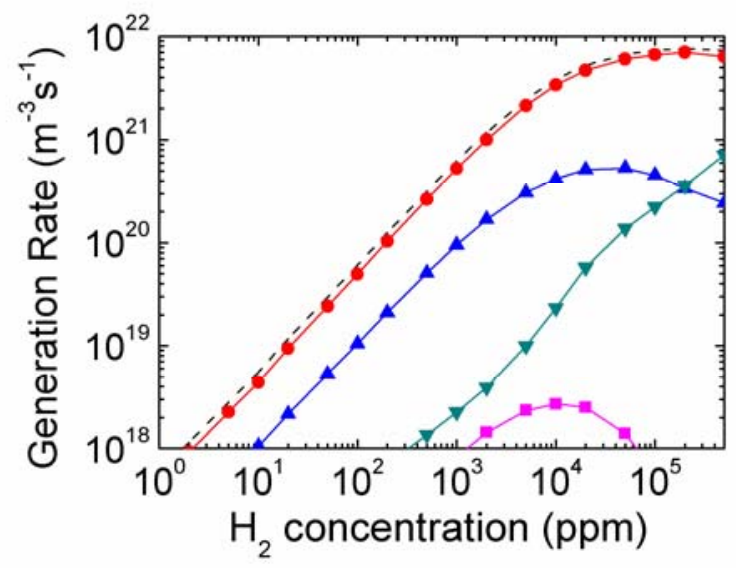

(a) 


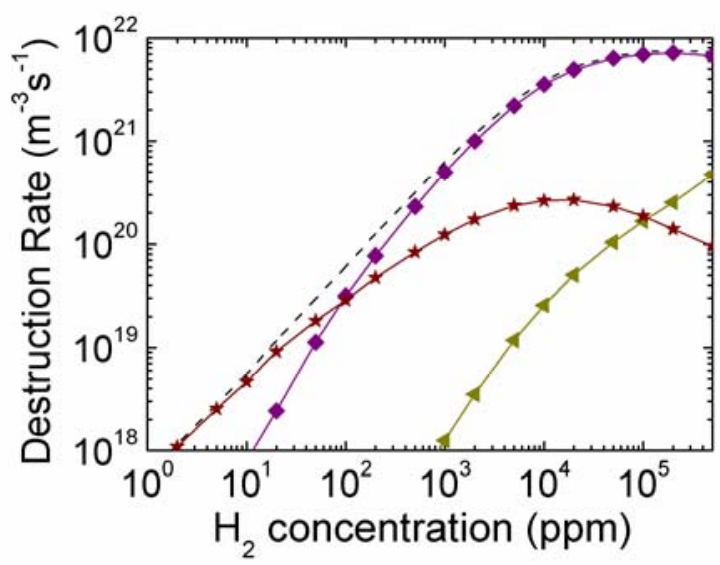

(b)

Fig.4 Processes contributing to (a) generation and (b) loss of $\mathrm{H}^{-}$

-.-: Total rate; $-\bullet-$ : Dissociative attachment of $\mathrm{H}_{2} ;-\bullet$ :Dissociative attachment of $\mathrm{H}_{2}(\mathrm{v}=1 \sim 3) ; \neg$ :

Dissociative attachment of $\mathrm{H}_{2}\left(v^{\prime \prime}\right)$; - - - Dissociative attachment of $\mathrm{H}_{2}(\mathrm{R}) ;-\bullet: \mathrm{H}^{-}+\mathrm{H}^{-} \rightarrow \mathrm{H}_{2}+e$;

$\rightarrow$ : Collisional detachment by $\mathrm{H}_{2}(\mathrm{v}=1 \sim 3) ; \rightarrow-$ : Recombination

From an application point of view, it is of interest to unravel the mechanisms involved in the production of atomic hydrogen $\mathrm{H}$. The generation and loss mechanisms as a function of the $\mathrm{H}_{2}$ concentration are shown in Fig.5a and Fig.5b, respectively. At low hydrogen concentration $\left(\left[\mathrm{H}_{2}\right]<10 \mathrm{ppm}\right)$, the ion-neutral reactions (mainly $\mathrm{R} 94: \mathrm{H}_{2}^{+}+\mathrm{He} \rightarrow \mathrm{HeH}^{+}+\mathrm{H}$ ) dominate the generation processes of $\mathrm{H}$. At these low $\mathrm{H}_{2}$ concentrations, Penning ionization is very effective, leading to the generation of $\mathrm{H}_{2}{ }^{+}$, which rapidly reacts with helium atoms to release $\mathrm{H}$. However, higher $\mathrm{H}$ density can be obtained when the $\mathrm{H}_{2}$ content is larger than 50ppm (Fig. 2). Under these conditions, the main generation mechanism of $\mathrm{H}$ is electron impact dissociation (R23), which reaches a maximum rate at $\left[\mathrm{H}_{2}\right] \sim 2 \%$. The decreasing rate at higher $\mathrm{H}_{2}$ concentrations is attributed to the decrease of both electron density (see Fig.1) and electron temperature as more input power is coupled into vibrational excitation of $\mathrm{H}_{2}$ (section 3.3). Other generation processes, such as electronion recombination, electron impact dissociation of $\mathrm{H}_{2}(v)$ and reactions between neutral species, have negligible contribution. At low $\mathrm{H}_{2}$ concentration Penning ionization (R118 and R121) leads to the loss of atomic $\mathrm{H}$ (Fig. 5b) but at higher concentrations three-body recombination reactions (mainly R128 and R130) dominate the loss mechanism.

For a $\mathrm{H}_{2}$ concentration of $\sim 2 \%$ that leads to the maximum $\mathrm{H}$ production (Fig. 1), the production 
of $\mathrm{H}$ is dominated by electron impact dissociation R23:e+ $H_{2} \rightarrow 2 \mathrm{H}+e$ and balanced by the loss via R128: $2 \mathrm{H}+\mathrm{He} \rightarrow \mathrm{H}_{2}+\mathrm{He}$. Therefore, an increase in electron and gas temperature (rate coefficient of R128 is inversely proportional to the gas temperature) would improve $\mathrm{H}$ production efficiency.

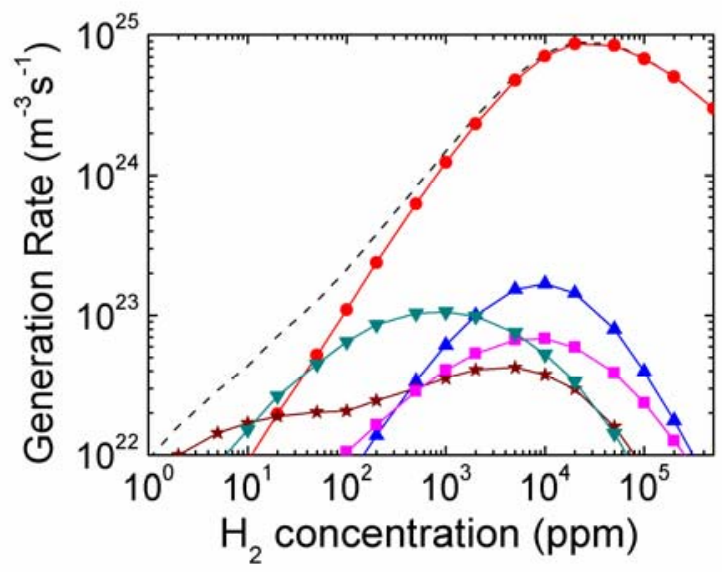

(a)

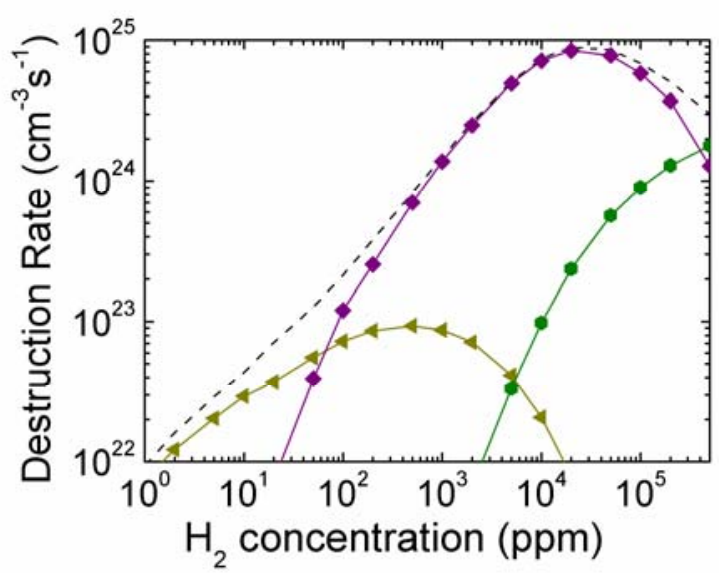

(b)

Fig.5 Processes contributing to (a) generation and (b) loss of ground state $\mathrm{H}$

- - -: Total rate; - - Electron impact dissociation of $\mathrm{H}_{2} ;-\bullet$ : Electron impact dissociation of $\mathrm{H}_{2}(v)$;

$\neg$ : Electron-ion recombination; $-\boldsymbol{-}-$ : Reactions with neutrals; $\rightarrow$ : Ion-neutral reactions; $-\neg$ :

$$
2 \mathrm{H}+\mathrm{He} \rightarrow \mathrm{H}_{2}+\mathrm{He} ;-2 \mathrm{H}+\mathrm{H}_{2} \rightarrow 2 \mathrm{H}_{2} ;- \text { : Penning ionization }
$$

\subsection{Power dissipation}

Fig. 6 shows the main power dissipation channels in $\mathrm{He}+\mathrm{H}_{2}$ plasmas as a function of the $\mathrm{H}_{2}$ concentration. For $\mathrm{H}_{2}$ concentrations below $2 \%$, most of the power delivered to the plasma is 
dissipated via elastic (momentum transfer) collisions. This is due to the large collisionality encountered in atmospheric-pressure plasmas and the relative efficient energy transfer due to the light atomic weight of helium. Similar trends have been reported in $\mathrm{He}+\mathrm{O}_{2}{ }^{[14]}, \mathrm{He}+\mathrm{H}_{2} \mathrm{O}^{[15]}$ plasmas .

At high $\mathrm{H}_{2}$ concentrations $\left(\left[\mathrm{H}_{2}\right]>2 \%\right)$, however, the main power dissipation channel switches to inelastic processes, in particular to vibrational excitation of $\mathrm{H}_{2}$. It is noted that vibrational excitation in $\mathrm{He}+\mathrm{H}_{2}$ plasmas is much more efficient than in admixtures of other molecular gases (e.g. $\mathrm{He}+\mathrm{O}_{2}{ }^{[15]}$ ) due to the large cross sections for vibrational excitation of $\mathrm{H}_{2}$ and the low energy of these states $\left(0.516\right.$ to $1.46 \mathrm{eV}$ for $\left.\mathrm{H}_{2}(v=1 \sim 3)^{[38]}\right)$. As a result, vibrational excitation becomes the main power dissipation mechanism when $\left[\mathrm{H}_{2}\right]>2 \%$ and therefore although vibrational excitation to $\mathrm{H}_{2}(v=1 \sim 3)$ have been neglected in some studies of low-pressure plasmas ${ }^{[7,39]}$, this should be taking into account in atmospheric-pressure discharges. In fact the rapid drop in electron density observed in Fig. 1 is a consequence of the increase in energy lost into vibrational excitation and neglecting vibrational excitation would result in a different electron density trend.

Power coupling into other inelastic collision processes required to maintain the discharge, such as electronic excitation, ionization and dissociation, is most efficient for hydrogen concentrations around $\sim 2 \%$ (Fig. 6 ), when $\sim 24 \%$ of the input power is coupled into them.

In addition to the power coupled into the electrons and dissipated via elastic and inelastic collisions (Fig. 6), 3-4\% of the input power is directly coupled to the ions (see discussion accompanying Eq.(2) and Eq.(3)).

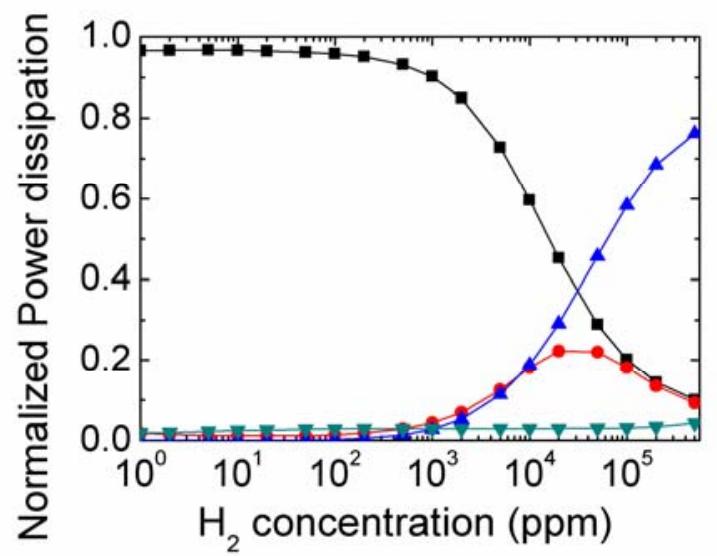

Fig.6 Power dissipation as a function of $\mathrm{H}_{2}$ concentration

$\rightarrow-$ Elastic collisions; $\rightarrow$ - Vibrational excitation of $\mathrm{H}_{2} ; \rightarrow-$ : Ion Joule heating; $-\bullet-$ : Other inelastic collisions 


\subsection{Main species and chemical reactions}

The model used in this study incorporates a fairly large number of species and reactions. While these can be easily handled by a global model, it is of interest to identify a subset of reactions that can capture the main physic-chemical processes but with reduced numerical demands. Such a reduced model could then be used in computationally-expensive models, such as multi-dimensional fluid models and particle-in-cell simulations.

The criteria used to identify the main species and reactions are the ones detailed in Ref. [15]. In brief, once the simulation has reached steady state, species with density larger than $5 \%$ of the total positive ions density are deemed to be important, and reactions with a contribution to particle balance of one key species above $5 \%$ are deemed to be key chemical pathways. In addition, some intermediate species that do not reach the threshold density but contribute significantly to the particle balance of a more abundant species are also considered. For example, $\mathrm{H}_{2}{ }^{+}$has very low density but it is an important precursor of $\mathrm{H}_{3}{ }^{+}$and therefore it is also included.

Applying the above criteria, two chemical sets are proposed. One for $\mathrm{He}+\mathrm{H}_{2}$ plasmas with low $\mathrm{H}_{2}$ concentration (RG1) and another one for plasmas with a high $\mathrm{H}_{2}$ concentration (RG2):

- Regime 1 (RG1): Discharges containing 1-5000ppm of hydrogen. In this regime, plasma species originated from helium are abundant and electron (ion) production is mainly ascribed to Penning processes. The density of hydrogen anions is very low in this regime and the plasma is clearly electropositive. The input power is mainly consumed by momentum transfer collisions between electrons and background helium.

- Regime 2 (RG2): Discharges containing 0.5-50\% of hydrogen. In this regime, the density of helium containing ions is negligible. Dissociative attachment and collisional detachment processes are important and vibrational excitation of $\mathrm{H}_{2}$ molecules absorbs most of the input power.

15 main species and 41 key reactions are identified for regime RG1, whereas 14 main species and 29 key reactions are proposed for regime RG2. These species and reactions are identified in Table 1, and Table A1. It is noted that a further reduction can be accomplished if different vibrational states can be combined into an "effective" vibrational state. This is possible because as indicated in Fig. 7, population of vibrational states do not interact significantly with the rest of the discharge chemistry and electron impact excitation and collisional quenching control primarily their balance. 


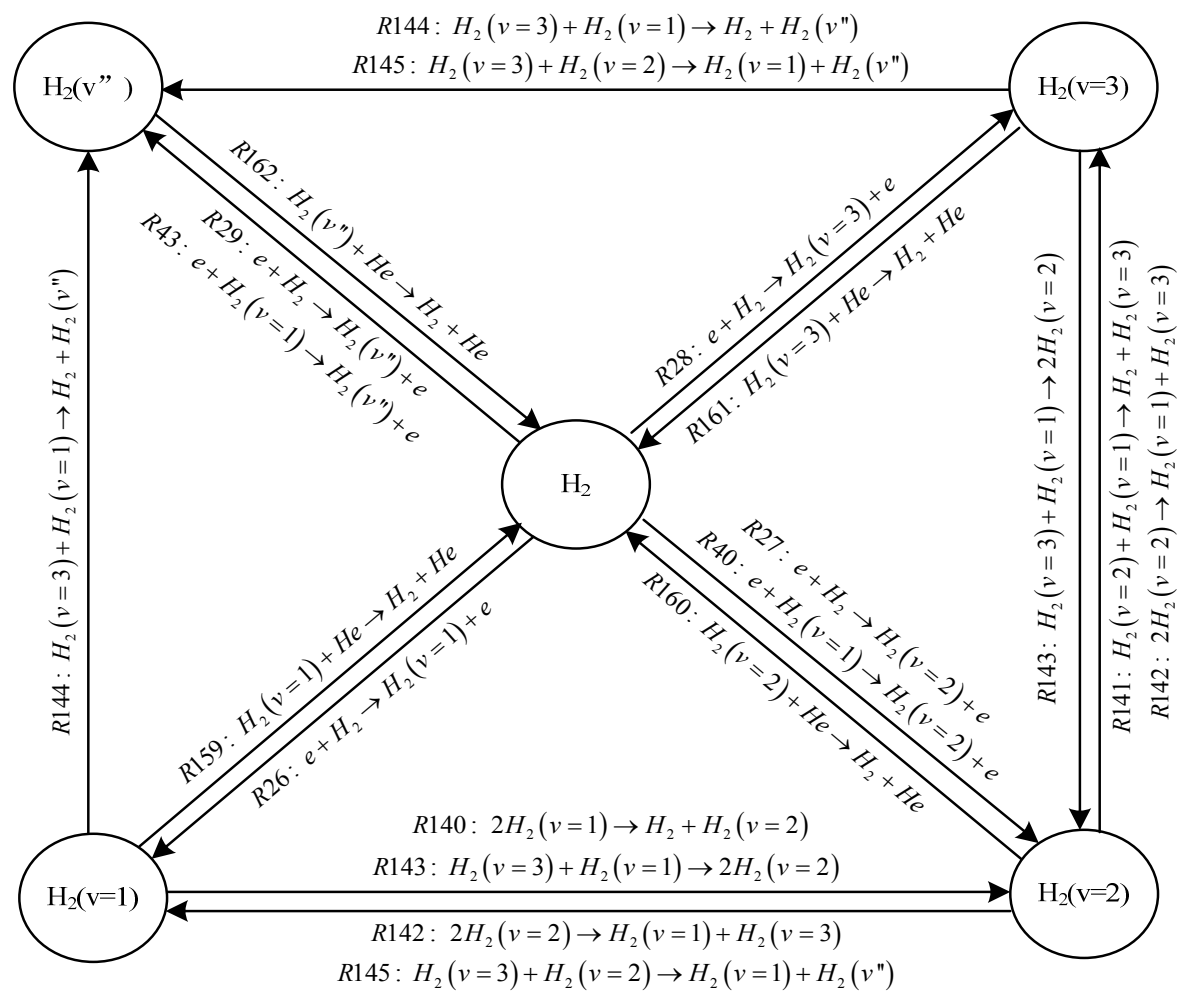

Fig.7 Main reactions for the generation/loss of $\mathrm{H}_{2}(\mathrm{v})$

\section{Effect of power modulationon plasma-induced species}

The results discussed in previous sections assume that the instantaneous input voltage $(P(t))$ varies according to $P(t)=\frac{\pi}{2} P_{\text {ave }}|\sin (\omega t)|$. This is an approximation of the actual time evolution of the instantaneous power delivered to the discharge and therefore it is important to assess the dependence of the results on this approximation. To this end, four different input power waveforms with the same average input power $\left(40 \mathrm{~W} / \mathrm{cm}^{3}\right)$ have been simulated: constant power, absolute value of asinusoidal waveform, square pulse with a $50 \%$ duty cycle and square pulse with a $25 \%$ duty cycle. Figure 8 compares the phase-average density of various plasma species. For the sake of clarity, the main plasma-induced species (Table 1) have been grouped into six categories: electrons, helium containing ions (e.g. $\mathrm{He}^{+}, \mathrm{He}_{2}{ }^{+}$and $\mathrm{HeH}^{+}$), hydrogen ions (e.g. $\mathrm{H}^{+}, \mathrm{H}_{2}{ }^{+}, \mathrm{H}_{3}{ }^{+}$and $\mathrm{H}^{-}$), helium metastables $\left(\mathrm{He}^{*}\right.$ and $\left.\mathrm{He}_{2}{ }^{*}\right)$, atomic hydrogen $(\mathrm{H})$ and vibrational excited hydrogen $\left(\mathrm{H}_{2}(v)\right)$. 

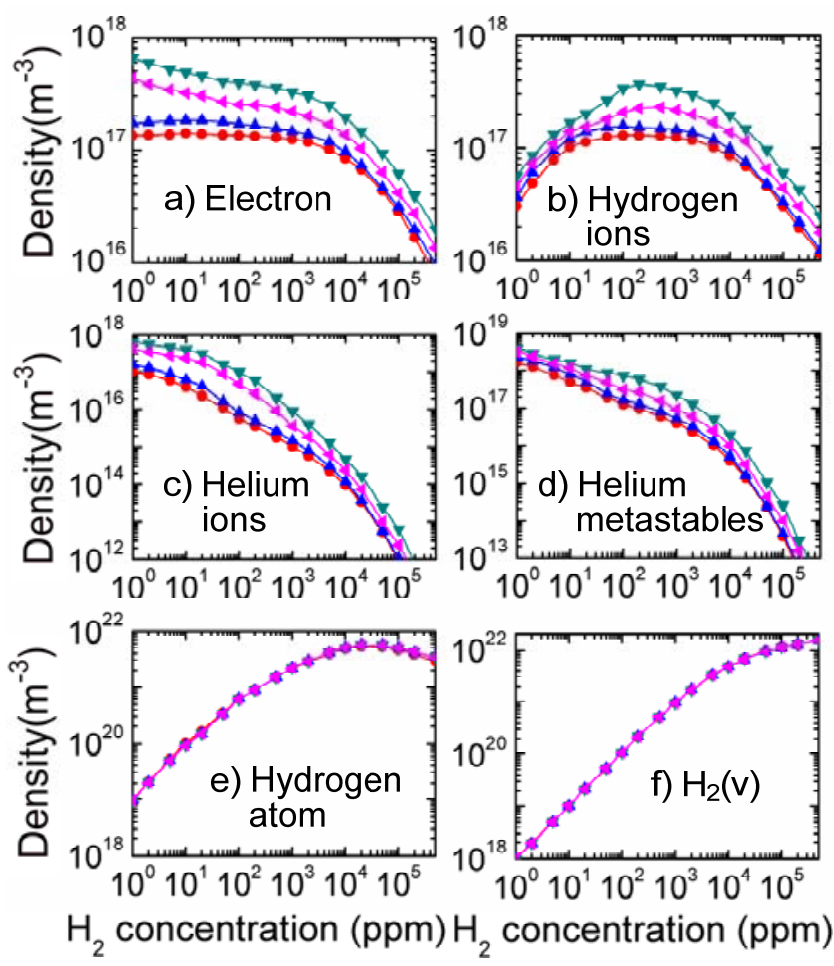

Fig.8 Densities of plasma species for different input power waveforms $\left(40 \mathrm{~W} / \mathrm{cm}^{3}\right)$ :

$\rightarrow$ : Constant; $\neg-$ : Absolute Sinusoidal; $\neg$ : Pulsed (duty cycle=50\%); $\neg$ : Pulsed (duty cycle $=25 \%)$

As shown in Fig. 8, the density of atomic $\mathrm{H}$ and $\mathrm{H}_{2}(\mathrm{v})$ are quite insensitive to the actual evolution of the input power and this is true for species requiring low electron energies for their formation. Differences, however, are found in the average density of excited and charged species. The evolution of the electron temperature during one cycle is shown in Fig.9 for each of the four input power waveforms. It can be seen that the maximum electron temperature increases from $T_{\mathrm{e}} \sim 2.5 \mathrm{eV}$ for the constant input power up to $3.25 \mathrm{eV}$ for the square pulse with $25 \%$ duty cycle. Due to the nonlinear dependence of excitation/ionization rate on the electron temperature, the pulsed power with $25 \%$ duty cycle is the most efficient in generating species that require impact with high energy electrons, such as helium metastables $\left(\varepsilon_{\mathrm{th}}=19.8 \mathrm{eV}\right)$ and hydrogen ion $\left(\varepsilon_{\mathrm{th}}=15.4 \mathrm{eV}\right)$, helium ion $\left(\varepsilon_{\mathrm{th}}=24.6 \mathrm{eV}\right)$. This also results in an enhancement of electron generation via Penning processes (relaxation of helium metastables) and electron impact ionization of $\mathrm{He}$ and $\mathrm{H}_{2}$. No significant difference is observed in the density of species that require lower energy. 


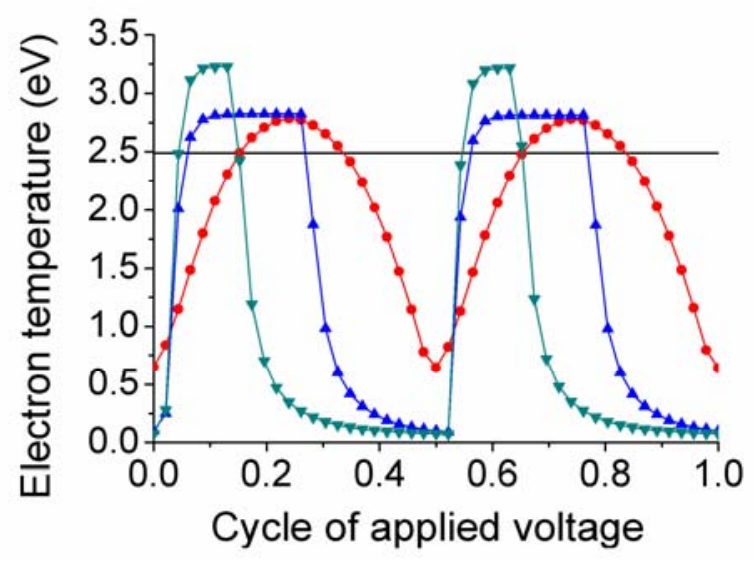

Fig. 9 The evolution of electron temperature in an applied voltage cycle

—: Constant; $\rightarrow-$ : Sinusoidal; $-\bullet$ : Pulsed (duty cycle $=50 \%$ ); $\neg$ : Pulsed (duty cycle=25\%)

\section{Conclusion}

Low-temperature atmospheric-pressure $\mathrm{He}+\mathrm{H}_{2}$ plasmas have been numerically studied by means of a global model over a wide range of $\mathrm{H}_{2}$ concentrations ( $1 \mathrm{ppm}$ to $50 \%$ ). The model incorporates a large set of species and reactions (20 species and 166 chemical reactions), which were identified after an extensive literature review. Two reduced sets of reactions (one for plasmas with a $\mathrm{H}_{2}$ concentration below $0.5 \%$ and one for plasmas with $\mathrm{H}_{2}$ concentrations above $0.5 \%$ ) have been proposed to minimize the computational demands of the chemistry model while still capturing the main physic-chemical processes.

It is found that the plasma density decreases rapidly at higher hydrogen concentration of $\left[\mathrm{H}_{2}\right]>0.2 \%$ due to the increasing energy invested in vibrational excitation of $\mathrm{H}_{2}$ molecules. $\mathrm{H}^{-}$is identified as the main anion and its production mechanism differs from that in low pressure discharges. At atmospheric pressure, and due to the large collisional relaxation of vibrationally excited molecules and Rydberg states, dissociative attachment of ground state hydrogen is found to be the main $\mathrm{H}^{-}$ production mechanism. The density of $\mathrm{H}^{-}$increases monotonically with $\mathrm{H}_{2}$ concentration although it remains smaller than the electron density for the conditions studied here.

From an application point of view, it is of interest to identify the conditions that lead to the largest production of atomic $\mathrm{H}$. It is found that this occurs when the hydrogen density is $\sim 2 \%$. At lower $\mathrm{H}_{2}$ concentrations there is less hydrogen available in the gas whereas at higher concentrations the increasing energy lost in vibrational excitation and the increase in three-body recombination 
involving $\mathrm{H}_{2}$ result in a less efficient $\mathrm{H}$ production.

Due to the large collisionality of atmospheric pressure plasmas, the electron temperature is expected to be markedly time-modulated. It is found that although the input power waveform have a significant impact on the density of excited and ionic species, species with low energy threshold for the formation such as hydrogen atom and vibrational excited states of $\mathrm{H}_{2}$ are fairly insensitive to the actual waveform of the input power.

\section{Acknowledgement}

The authors would like to thank Dr. Peter Bruggeman (Eindhoven University, The Netherland) for fruitful discussions related to this work. This work was supported by the Fundamental Research Funds for the Central Universities of China, the State Key Laboratory of Electrical Insulationand Power Equipment (No. EIPE11108 and EIPE12301) and the Engineering Physical Science Research Council (UK). 


\section{Appendix}

\section{Table A1. Chemical reactions included in the models}

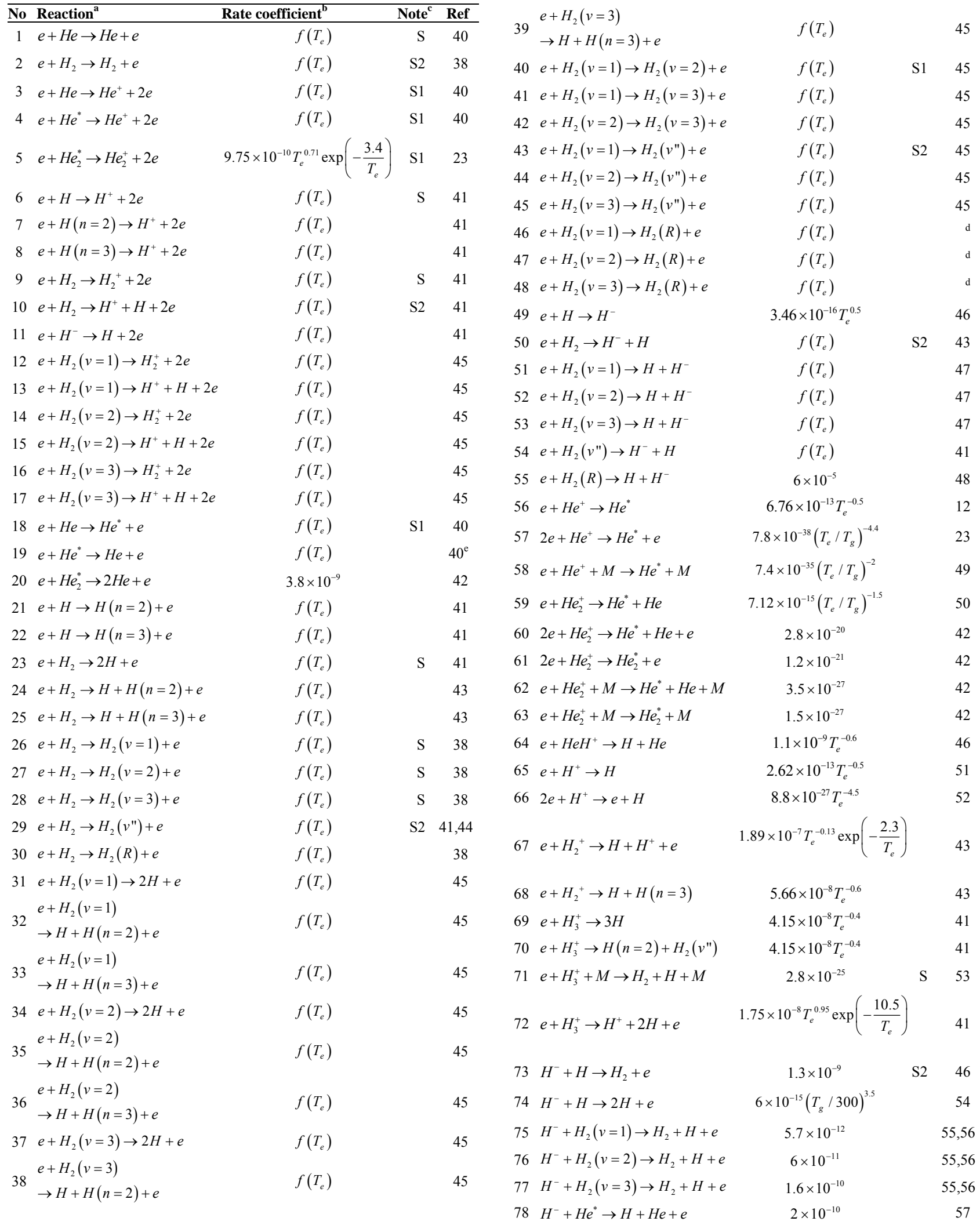




\begin{tabular}{|c|c|c|c|c|c|c|c|c|}
\hline $79 \mathrm{H}^{-}+\mathrm{He}_{2}^{*} \rightarrow \mathrm{H}+2 \mathrm{He}+e$ & $2 \times 10^{-10}$ & & 57 & 123 & $H(n=2)+H_{2} \rightarrow H_{3}^{+}+e$ & $1.4 \times 10^{-11}\left(T_{g} / 300\right)^{0.5}$ & & 65 \\
\hline $80 \mathrm{He}^{+}+2 \mathrm{He} \rightarrow \mathrm{He}_{2}^{+}+\mathrm{He}$ & $1.4 \times 10^{-31}\left(T_{g} / 300\right)^{-0.6}$ & S1 & 23 & 124 & $H(n=3)+H_{2} \rightarrow H_{3}^{+}+e$ & $4.83 \times 10^{-10}\left(T_{g} / 300\right)^{0.5}$ & & 54 \\
\hline $81 \mathrm{He}^{+}+H \rightarrow H^{+}+\mathrm{He}$ & $1.9 \times 10^{-15}$ & & 46 & 125 & $\mathrm{He}^{*}+\mathrm{He} \rightarrow 2 \mathrm{He}$ & $5.8 \times 10^{-15}$ & S1 & 66 \\
\hline $82 \mathrm{He}^{+}+\mathrm{H} \rightarrow \mathrm{HeH}^{+}$ & $1.58 \times 10^{-15}\left(T_{g} / 300\right)^{-0.3}$ & & 58 & 126 & $\mathrm{He}^{*}+2 \mathrm{He} \rightarrow \mathrm{He}_{2}^{*}+\mathrm{He}$ & $2 \times 10^{-34}$ & S1 & 50 \\
\hline $83 \mathrm{He}^{+}+\mathrm{H}_{2} \rightarrow \mathrm{H}^{+}+\mathrm{H}+\mathrm{He}$ & $3.7 \times 10^{-14} \exp \left(-35 / T_{g}\right)$ & & 46 & 127 & $2 \mathrm{H} \rightarrow \mathrm{H}_{2}$ & $6.04 \times 10^{-33}\left(T_{g} / 298\right)^{-1}$ & & 67 \\
\hline $84 \mathrm{He}^{+}+\mathrm{H}_{2} \rightarrow \mathrm{H}_{2}^{+}+\mathrm{He}$ & $7.2 \times 10^{-15}$ & & 46 & 128 & $2 \mathrm{H}+\mathrm{He} \rightarrow \mathrm{He}+\mathrm{H}_{2}$ & $5.8 \times 10^{-33}\left(T_{g} / 300\right)^{-1}$ & $\mathrm{~S}$ & 68 \\
\hline $85 \mathrm{He}_{2}^{+}+H \rightarrow H^{+}+2 \mathrm{He}$ & $3.5 \times 10^{-10}$ & S1 & $\mathrm{f}$ & & $3 H \rightarrow H+H_{2}$ & $6 \times 10^{-31}\left(T_{g} / 300\right)^{-1}$ & & 2 \\
\hline $86 \mathrm{He}_{2}^{+}+\mathrm{H}_{2} \rightarrow \mathrm{H}_{2}^{+}+2 \mathrm{He}$ & $3.5 \times 10^{-10}$ & S1 & 54 & & $2 \mathrm{H}+\mathrm{H}_{2} \rightarrow 2 \mathrm{H}_{2}$ & $8.1 \times 10^{-33}(T / 300)^{-0.6}$ & & \\
\hline $87 \mathrm{He}_{2}^{+}+\mathrm{H}_{2} \rightarrow \mathrm{HeH}^{+}+\mathrm{H}+\mathrm{He}$ & $1.76 \times 10^{-10}$ & S1 & 54 & & $2 \mathrm{H}+\mathrm{H}_{2} \rightarrow 2 \mathrm{H}_{2}$ & $8.1 \times 10=\left(I_{g} / 300\right)$ & $\mathrm{S} 2$ & 68 \\
\hline $88 \mathrm{HeH}^{+}+\mathrm{H} \rightarrow \mathrm{H}_{2}^{+}+\mathrm{He}$ & $9.1 \times 10^{-10}$ & S1 & 46 & & $\mathrm{He}_{2}^{*}+\mathrm{M} \rightarrow 2 \mathrm{He}+\mathrm{M}$ & $1.5 \times 10^{-15}$ & S1 & 50 \\
\hline $89 \mathrm{HeH}^{+}+\mathrm{H}_{2} \rightarrow \mathrm{H}_{3}^{+}+\mathrm{He}$ & $1.5 \times 10^{-9}$ & S1 & 46 & 132 & $H(n=2)+H e \rightarrow H+H e$ & $2.7 \times 10^{-13}$ & & 69 \\
\hline $90 \mathrm{H}^{+}+\mathrm{He} \rightarrow \mathrm{HeH}^{+}$ & $8.4 \times 10^{-19}\left(T_{g} / 300\right)^{-4.5}$ & & 59 & $\begin{array}{l}133 \\
134\end{array}$ & $\begin{array}{l}H(n=2)+\mathrm{H}_{2} \rightarrow \mathrm{H}+\mathrm{H}_{2} \\
\mathrm{H}(n=3)+\mathrm{He} \rightarrow \mathrm{H}+\mathrm{He}\end{array}$ & $2.1 \times 10^{-11}$ & & 52 \\
\hline $91 H^{+}+2 H_{2} \rightarrow H_{3}^{+}+H_{2}$ & $3.1 \times 10^{-29}\left(T_{g} / 300\right)^{-0.5}$ & S2 & 54 & 135 & $\mathrm{H}(n=3)+\mathrm{H}_{2} \rightarrow \mathrm{H}+\mathrm{H}_{2}$ & $\begin{array}{l}1 \times 10^{-11} \\
2 \times 10^{-9}\end{array}$ & & 70 \\
\hline $92 \mathrm{H}^{+}+\mathrm{H}_{2}+\mathrm{He} \rightarrow \mathrm{H}_{3}^{+}+\mathrm{He}$ & $1.5 \times 10^{-29}$ & $\mathrm{~S}$ & 60 & 136 & $H_{2}(v=1)+H_{2} \rightarrow 2 H_{2}$ & $1 \times 10^{-16}\left(T_{g} / 300\right)^{4.5}$ & & 71 \\
\hline $93 \quad H^{+}+H+M \rightarrow H_{2}^{+}+M$ & $1 \times 10^{-34}$ & & 61 & & $H_{2}(v=2)+H_{2}$ & & & \\
\hline $94 \mathrm{H}_{2}^{+}+\mathrm{He} \rightarrow \mathrm{HeH}^{+}+\mathrm{H}$ & $1.3 \times 10^{-10}$ & S1 & 46 & 137 & $\rightarrow H_{2}+H_{2}(v=1)$ & $2.2 \times 10^{-16}$ & & 2 \\
\hline $95 H_{2}^{+}+H \rightarrow H^{+}+H_{2}$ & $6.39 \times 10^{-10}$ & & 52 & & $H_{2}(v=3)+H_{2}$ & & & \\
\hline $96 \mathrm{H}_{2}^{+}+\mathrm{H}_{2} \rightarrow \mathrm{H}_{3}^{+}+\mathrm{H}$ & $2.1 \times 10^{-9}$ & S2 & 54 & 138 & $\rightarrow H_{2}+H_{2}(v=2)$ & $4.9 \times 10^{-16}$ & & 12 \\
\hline $97 \mathrm{H}_{3}^{+}+\mathrm{He}^{*} \rightarrow \mathrm{H}_{2}+\mathrm{H}^{+}+\mathrm{He}$ & $1 \times 10^{-10}$ & & 57 & 139 & $H_{2}\left(v^{\prime \prime}\right)+H_{2} \rightarrow H_{2}+H_{2}(v=3)$ & $1.07 \times 10^{-15}$ & & $72^{\mathrm{g}}$ \\
\hline $98 \mathrm{H}_{3}^{+}+\mathrm{He}_{2}^{*} \rightarrow \mathrm{H}_{2}+\mathrm{H}^{+}+2 \mathrm{He}$ & $1 \times 10^{-10}$ & & 57 & 140 & $H_{2}(v=1)+H_{2}(v=1)$ & $7.6 \times 10^{-13}$ & $\mathrm{~S}$ & 73 \\
\hline $99 \mathrm{H}^{-}+\mathrm{He}^{+} \rightarrow \mathrm{H}+\mathrm{He}$ & $2.3 \times 10^{-7}\left(T_{g} / 300\right)^{-0.5}$ & & 46 & & $\rightarrow H_{2}+H_{2}(v=2)$ & & & \\
\hline $100 \mathrm{H}^{-}+\mathrm{He}_{2}^{+} \rightarrow \mathrm{H}+2 \mathrm{He}$ & $2 \times 10^{-7}\left(T_{g} / 300\right)^{-0.5}$ & & 28 & 141 & $\begin{array}{l}H_{2}(v=2)+H_{2}(v=1) \\
H_{2}+H_{2}(v=3)\end{array}$ & $1.1 \times 10^{-12}$ & $\mathrm{~S}$ & 3 \\
\hline $101 \mathrm{H}^{-}+\mathrm{HeH}^{+} \rightarrow \mathrm{H}_{2}+\mathrm{He}$ & $1 \times 10^{-7}$ & & 28 & & $H_{2}(v=2)+H_{2}(v=2)$ & & & \\
\hline $102 H^{-}+H^{+} \rightarrow H(n=2)+H$ & $9 \times 10^{-11}\left(T_{g} / 300\right)^{0.83}$ & & 49 & 142 & $\rightarrow H_{2}(v=1)+H_{2}(v=3)$ & $2.28 \times 10^{-12}$ & S2 & 72 \\
\hline $103 H^{-}+H^{+} \rightarrow H(n=3)+H$ & $1.8 \times 10^{-7}\left(T_{g} / 300\right)^{-0.5}$ & & 49 & 143 & $H_{2}(v=3)+H_{2}(v=1)$ & $8.1 \times 10^{-13}$ & S2 & 73 \\
\hline $104 \mathrm{H}^{-}+\mathrm{H}_{2}^{+} \rightarrow \mathrm{H}+\mathrm{H}_{2}$ & $2 \times 10^{-7}\left(T_{g} / 300\right)^{-0.5}$ & & 54 & & $\begin{array}{l}\rightarrow H_{2}(v=2)+H_{2}(v=2) \\
H(y=3)+H_{0}(v=1)\end{array}$ & & & \\
\hline $105 \mathrm{H}^{-}+\mathrm{H}_{3}^{+} \rightarrow 2 \mathrm{H}_{2}$ & $2 \times 10^{-7}\left(T_{g} / 300\right)^{-0.5}$ & & 54 & 144 & $\begin{array}{l}H_{2}(v=3)+H_{2}(v=1) \\
\rightarrow H_{2}+H_{2}\left(v^{\prime \prime}\right)\end{array}$ & $8.4 \times 10^{-13}$ & S2 & 72 \\
\hline $106 \mathrm{H}^{-}+\mathrm{He}^{+}+\mathrm{M} \rightarrow \mathrm{H}+\mathrm{He}+\mathrm{M}$ & $2 \times 10^{-25}\left(T_{g} / 300\right)^{-2.5}$ & & 28 & 145 & $H_{2}(v=3)+H_{2}(v=2)$ & $29 \times 10^{-12}$ & 2 & \\
\hline $107 \mathrm{H}^{-}+\mathrm{He}_{2}^{+}+\mathrm{M} \rightarrow \mathrm{H}+2 \mathrm{He}+\mathrm{M}$ & $2 \times 10^{-25}\left(T_{g} / 300\right)^{-2.5}$ & & 28 & & $\rightarrow H_{2}(v=1)+H_{2}\left(v^{\prime \prime}\right)$ & $2.9 \times 10$ & $\mathrm{SL}$ & \\
\hline $108 H^{-}+H^{+}+M \rightarrow 2 H+M$ & $2 \times 10^{-25}\left(T_{g} / 300\right)^{-2.5}$ & & 28 & 146 & $\begin{array}{l}H_{2}(v=3)+H_{2}(v=3) \\
\rightarrow H_{2}(v=2)+H_{2}\left(v^{\prime \prime}\right)\end{array}$ & $4.56 \times 10^{-12}$ & & 72 \\
\hline $109 H^{-}+H_{2}^{+}+M \rightarrow H+H_{2}+M$ & $2 \times 10^{-25}\left(T_{g} / 300\right)^{-2.5}$ & & 28 & 147 & $H_{2}(v=1)+H_{2}\left(v^{\prime \prime}\right)$ & $7 \times 10^{-13}$ & & $77^{\mathrm{g}}$ \\
\hline $110 H^{-}+H_{3}^{+}+M \rightarrow 2 H+H_{2}+M$ & $2 \times 10^{-25}\left(T_{g} / 300\right)^{-2.5}$ & S2 & 28 & 147 & $\rightarrow H_{2}(v=2)+H_{2}(v=3)$ & $4.1 \times 10$ & & 12 \\
\hline $111 \begin{array}{c}H^{-}+\mathrm{HeH}^{+}+M \\
\rightarrow 2 H+\mathrm{He}+M\end{array}$ & $2 \times 10^{-25}\left(T_{g} / 300\right)^{-2.5}$ & & 28 & 148 & $\begin{array}{l}H_{2}(v=2)+H_{2}(v ") \\
\rightarrow H_{2}(v=3)+H_{2}(v=3)\end{array}$ & $1.6 \times 10^{-12}$ & & $72^{\mathrm{g}}$ \\
\hline $1122 \mathrm{He}^{*} \rightarrow \mathrm{He}_{2}^{+}+e$ & $2.03 \times 10^{-9}\left(T_{g} / 300\right)^{0.5}$ & S1 & 23 & 149 & $H_{2}(v=1)+H \rightarrow H+H_{2}$ & $4.2 \times 10^{-14}$ & & 74 \\
\hline $1132 \mathrm{He}^{*} \rightarrow \mathrm{He}^{+}+\mathrm{He}+e$ & $8.7 \times 10^{-10}\left(T_{g} / 300\right)^{0.5}$ & S1 & 23 & 150 & $H_{2}(v=2)+H \rightarrow H+H_{2}$ & $5.9 \times 10^{-13}$ & & 4 \\
\hline $114 \mathrm{He}^{*}+\mathrm{He}_{2}^{*} \rightarrow \mathrm{He}^{+}+2 \mathrm{He}+e$ & $5 \times 10^{-10}$ & S1 & 42 & 151 & $H_{2}(v=2)+H \rightarrow H+H_{2}(v=1)$ & $3 \times 10^{-13}$ & & 74 \\
\hline $115 \mathrm{He}^{*}+\mathrm{He}_{2}^{*} \rightarrow \mathrm{He}_{2}^{+}+\mathrm{He}+e$ & $2 \times 10^{-9}$ & $\mathrm{~S} 1$ & 42 & 152 & $H_{2}(v=3)+H \rightarrow H+H_{2}$ & $1.5 \times 10^{-12}$ & & 74 \\
\hline $1162 \mathrm{He}_{2}^{*} \rightarrow \mathrm{He}^{+}+3 \mathrm{He}+e$ & $3 \times 10^{-10}$ & S1 & 42 & 153 & $H_{2}(v=3)+H \rightarrow H+H_{2}(v=1)$ & $1.6 \times 10^{-12}$ & & 74 \\
\hline $1172 \mathrm{He}_{2}^{*} \rightarrow \mathrm{He}_{2}^{+}+2 \mathrm{He}+e$ & $1.2 \times 10^{-9}$ & S1 & 42 & 154 & $H_{2}(v=3)+H \rightarrow H+H_{2}(v=2)$ & $2 \times 10^{-12}$ & & 74 \\
\hline $118 \mathrm{He}^{*}+\mathrm{H} \rightarrow \mathrm{H}^{+}+\mathrm{He}+e$ & $1.1 \times 10^{-9}$ & S1 & 44 & 155 & $H_{2}\left(v^{\prime \prime}\right)+H \rightarrow H+H_{2}$ & $4.3 \times 10^{-12}$ & & $74^{\mathrm{g}}$ \\
\hline $119 \mathrm{He}^{*}+\mathrm{H}_{2} \rightarrow \mathrm{H}_{2}^{+}+\mathrm{He}+e$ & $2.9 \times 10^{-11}$ & S1 & 62,63 & 156 & $H_{2}\left(v^{\prime \prime}\right)+H \rightarrow H+H_{2}(v=1)$ & $4.2 \times 10^{-12}$ & & $74^{\mathrm{g}}$ \\
\hline $120 \mathrm{He}^{*}+\mathrm{H}_{2} \rightarrow \mathrm{H}+\mathrm{HeH}^{+}+e$ & $3 \times 10^{-12}$ & S1 & 62,63 & 157 & $H_{2}\left(v^{\prime \prime}\right)+H \rightarrow H+H_{2}(v=2)$ & $4.9 \times 10^{-12}$ & & $74^{\mathrm{g}}$ \\
\hline $121 \mathrm{He}_{2}^{*}+\mathrm{H} \rightarrow 2 \mathrm{He}+\mathrm{H}^{+}+e$ & $2.2 \times 10^{-10}$ & S1 & $\mathrm{f}$ & 158 & $H_{2}\left(v^{\prime \prime}\right)+H \rightarrow H+H_{2}(v=3)$ & $5.5 \times 10^{-12}$ & & $74^{\mathrm{g}}$ \\
\hline $122 \mathrm{He}_{2}^{*}+\mathrm{H}_{2} \rightarrow \mathrm{H}_{2}^{+}+2 \mathrm{He}+e$ & $2.2 \times 10^{-10}$ & S1 & 64 & 159 & $\mathrm{H}_{2}(v=1)+\mathrm{He} \rightarrow \mathrm{H}_{2}+\mathrm{He}$ & $2 \times 10^{-17}\left(T_{g} / 300\right)^{2.9}$ & $\mathrm{~S}$ & 75 \\
\hline
\end{tabular}




$\begin{array}{lcrr}160 H_{2}(v=2)+H e \rightarrow H_{2}+H e & 1.05 \times 10^{-16}\left(T_{g} / 300\right)^{3} & \mathrm{~S} & 75 \\ 161 H_{2}(v=3)+H e \rightarrow H_{2}+H e & 3.9 \times 10^{-16}\left(T_{g} / 300\right)^{3.3} & \mathrm{~S} & 75 \\ 162 H_{2}\left(v^{\prime \prime}\right)+H e \rightarrow H_{2}+H e & 1.1 \times 10^{-15}\left(T_{g} / 300\right)^{3.7} & \mathrm{~S} 2 & 75 \\ 163 H_{2}(R)+H_{2} \rightarrow H_{2}+2 H & 1.88 \times 10^{-9} & 36,76 \\ 164 H_{2}(R)+H e \rightarrow 2 H+H e & 8 \times 10^{-10} & 77 \\ 165 H(n=2) \rightarrow H+h v & 4.7 \times 10^{8} s^{-1} & 63 \\ 166 H(n=3) \rightarrow H+h v & 5.57 \times 10^{7} s^{-1} & 63 \\ 167 H(n=3) \rightarrow H(n=2)+h v & 4.41 \times 10^{7} s^{-1} & 63 \\ 168 H_{2}(R) \rightarrow H_{2}+h v & 1 \times 10^{6} s^{-1} & 37\end{array}$

${ }^{a} \mathrm{He}^{*}$ represents $\mathrm{He}\left(2^{3} \mathrm{~S}\right)$ and $\mathrm{He}\left(2^{1} \mathrm{~S}\right) ; \mathrm{He}_{2}{ }^{*}$ represents $\mathrm{He}_{2}\left(\mathrm{a}^{3} \Sigma_{\mathrm{u}}^{+}\right) ; \mathrm{H}_{2}\left(v^{\prime \prime}\right)$ represents $\mathrm{H}_{2}(\mathrm{v} \geq 4) ; \mathrm{H}_{2}(\mathrm{R})$ represents Rydberg states of $\mathrm{H}_{2} ; \quad M$ represents the background gases helium and hydrogen.

b) Rate coefficients have units of $\mathrm{cm}^{3} / \mathrm{s}$ for twobody reactions and $\mathrm{cm}^{6} / \mathrm{s}$ for three-body reactions; $T_{e}$ has units $\mathrm{eV} ; T_{g}$ has units $\mathrm{K}$. $f\left(T_{e}\right)$ indicates that the rate coefficient is obtained using the cross section from the indicated reference.

${ }^{c} \mathrm{~S}$ represents main reaction in the whole range of hydrogen concentration. S1: main reactions in $\mathrm{RG} 1$; $\mathrm{S} 2$ : main reactions in $\mathrm{RG} 2$; S3: main reactions in $\mathrm{RG} 3$.

${ }^{\mathrm{d})}$ Cross-section estimated by shifting the ground state cross section of $\mathrm{H} 2$ by the excitation threshold.

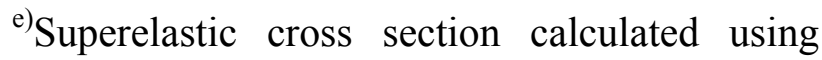
detailed balance.

${ }^{\mathrm{f})}$ Estimated same as $\mathrm{H}_{2}$.

${ }^{g}$ Using the rate coefficient of $\mathrm{H}_{2}(v=4)$ for $\mathrm{H}_{2}\left(v^{\prime \prime}\right)$.

\section{References}

[1] Goossens O, Dekempeneer E, Vangeneugden D, Leest de R V and Leys C 2001 Surf.Coat. Technol. 142-144 474

[2] Hsieh J H and Li C 2006Thin Solid Films504101

[3] Ohmi H, Kakiuchi H, Nishijima K, Watanabe H and Yasutake K 2006 Jpn. J. Appl. Phys.458488

[4] Koo I G, Lee M S and Lee W M 2006Thin Solid Films506-507350

[5] Nagai M, Hori M and Goto T 2005J. Appl. Phys.97123304

[6] Chaudhary K, Inomata K, Yoshimoto M and Koinuma H 2003 Mater.Lett.57 3406

[7] Hagelaar G J M, Kroesen G M W 2000 J. Appl. Phys.882252

[8] Harutyunyan A R, Chen G, Paronyan T M, Pigos E M, Kuznetsov O A, Hewaparakrama K, Kim S M, Zakharov D, Stach E A, Sumanasekera G U2009Science326116

[9] Matsushita A, Nagai M, Yamakawa K, Hiramatsu M, Sakai A, Hori M, Goto T and Zaima S 2004Jpn. J. Appl. Phys.43424

[10] KimSJ,LiebermanM A, LichtenbergAJ, GunmundssonJT 2006J. Vac. Sci. Technol. A242025

[11] Lieberman M A and Lichtenberg A J 2005 Principles of Plasma Discharges and Materials Processing (2nd edition) Wiley, NewYork

[12] Stafford D S and Kushner M J 2004 J. Appl. Phys. 962451

[13] Park G, Lee H, Kim G, Lee J K 2008Plamsa Process. Polym. 5569

[14] Liu D X, Rong M G, Wang X H, Iza F, Kong M G and Bruggeman P 2010Plasma Process.Polym.7846

[15] Liu D X, Bruggeman P, Iza F, Rong M Z and Kong M G 2010Plasma Sources Sci. Technol.19025018

[16] Liu D X, Iza F, Wang X H, Kong M G and Rong M Z 2011Appl. Phys. Lett.98221501

[17] Walsh J L, Liu D X, Iza F, Rong M Z and Kong M G 2010J. Phys. D: Appl. Phys.43032001

[18] Gudmundsson J T and Thorsteinsson E G2007Plasma Sources Sci. Technol.16 399

[19] Iza F, Lee J K and Kong M G 2007 Phys. Rev. Lett.99 075004

[20] Liu D W, Iza F and Kong M G 2009 Appl. Phys. Lett.95 031501

[21] YangA J, Wang X H, Rong M Z, Liu D X, Iza F and Kong M G 2011 Phys. Plasmas 18113503

[22] Veatch G E and Oskam H J 1973Phys. Rev. A8389

[23] Wang Q, Economou D J, and Donnelly V M 2006J. Appl. Phys.100023301

[24] Lazzaroni C, Chabert P, Lieberman M A, Lichtenberg A J and Leblanc A 2012 Plasma Sources Sci. Technol.21 035013

[25] MATLAB version 8.1.0.604 Natick, Massachusetts: The MathWorks Inc., 2013.

[26] Hagelaar G J M, Pitchford L C2005Plasma Sources Sci. Technol.14722

[27] Kushner M J 1999Bull. Am. Phys. Soc.4463

[28] Kossyi I A, Kostinsky A Y, Matveyev A A, Silakov V P 1992Plasma Sources Sci. Technol.1207 
[29] Martens T, Bogaerts A, Brok W J M and Dijk J V 2008Appl. Phys. Lett.92041504

[30] Bruggeman P, Iza F, Lauwers D and Gonzalvo Y A 2010J. Phys. D: Appl. Phys.43012003

[31] Qian M, Ren C, Wang D, Zhang J and Wei G 2010J. Appl. Phys. 107063303

[32] Koo G, Cho J H and Lee W M 2008Plasma Process.Polym.5161

[33] Zhou Q, Cheng C and Meng Y 2009Plasma Sci. Technol.11560

[34] Nojima H, Park R E, Kwon J H, Suh I, Jeon J, Ha E, On H K, Kim H R, Choi K H, Lee K H, Seong B L, Jung H, Kang S J, Namba S and Takiyama K 2007J. Phys. D: Appl. Phys.40501

[35] Patnaik P 2007A comprehensive guide to the hazardous properties of chemical substances. Wiley, New Jersey

[36] Hassouni K, Gicquel A and Capitelli M 1998Chem. Phys. Lett. 290502

[37] Capitelli M and Gorse C 2005IEEE Trans. Plasma Sci.331832

[38] Phelps A V1985 JILA Information Center Report No. 28

[39] Mendez I, Grodillo-Vazquez F J, Herrero V J and Tanarro I 2006J. Phys. Chem. A1106060

[40] BOLSIG+ software version 1.1. $2008 \mathrm{http}$ ://www.siglo-kinema.com/technical.htm

[41] Janev R K. Langer W D, Evans J K, Post J D E 1987 Springer, Berlin.

[42] Deloche R, Monchicourt P, Cheret M, and Lambert F 1976Phys. Rev. A131140

[43] Tawara H, Itikawa Y, Nishimura H, and Youshino M 1990J. Phys. Chem. Ref. Data19617

[44] Hagelaar G J M and Kroesen G M W 2000J. Appl. Phys.88 2252

[45] Celiberto R, Janev R K, Laricchiuta A, Capitelli M, Wadehra J M and Atems D E 2001 Atom. Data Nucl. Data Tables77 161

[46] Millar T J, Farquhar P R A, and Willacy K 1997Astron. Astrophys. Suppl. Ser.121139

[47] Gallup G A, Xu Y and Fabrikant I I 1998Phys. Rev. A572596

[48] Daskos P G, Pinnaduwage L A, and Kielkopf J F1997 Phys. Rev. A, Gen. Phys.554131

[49] Konstantinovskii R S, Shibkov V M, and Shibkova L V 2005Kinetics and Catalysis46775

[50] Golubovskii YB, Maiorov VA, Behnke J, Behnke JF 2003J. Phys. D: Appl. Phys.3639

[51] Salabas A, Marques L, Jolly J, Gousset G and Alves L L 2004J. Appl. Phys.954605

[52] Giuliani J L, Shamamian V A, Thomas R E, Apruzese J P, Mulbrandon M, Rudder R A, Hendry R C, Robson A E 1999IEEE Trans. Plasma Sci.271317

[53] Glosik J J, Korolov I, Plasil R, Novotny O, Kotrik T, Hlavenka P, Varju J, Greene C H, Kokoouline V and Mikhailov I A 2008J. Phys. B: At. Mol. Opt. Phys.41191001

[54] Hassouni K, Grotjohn T A, Gicquel A 1999 J. Appl. Phys.86134

[55] Phelps A V 1990J. Phys. Chem. Ref. Data19653

[56] Huq M S, Doverspike L D and Champion R L 1983Phys. Rev. A272831

[57] Vidmar R J, Stalder K R 2004Final report prepared for Air Force Office of Scientific Research. Report No.: AFRLSRARRE040123. Contract No: F49620-01-1-0414. Feb. 20.

[58] Kraemer W P, Spirko V, Jurek M 1995Chem. Phys. Lett.236 177

[59] Jurek M, Spirko V, Kraemer W P 1995Chem. Phys.193 287

[60] McLain J L, Poterya V, Molek C D, Babcock L M and Adams N G 2004J. Phys. Chem. A1086704

[61] Soloshenko I A, Tsiolko V V, Khomich V A, Bazhenov V Y, Ryabtsev A V, Schedrin A I, Mikhno I L $2002 I E E E$ Trans. Plasma Sci.301440

[62] Adams N G, Bohme D K, and Ferguson E E 1970J. Chem. Phys.525101

[63] Ivanov V A and Skoblo Y E 2005Optics and Spectroscopy98811

[64] Takao S, Kogoma M, Oka T, Imamura M and Arai S 1980J. Chem. Phys.73148

[65] Specht L T, Foster K D, and Muschlitz J E E 1975J. Chem. Phys. 631582

[66] Sommerer T J and Kushner M J 1992J. Appl. Phys. 711654

[67] NIST chemical kinetic database.http://kinetics.nist.gov/kinetics/index.jsp

[68] GRI-MECH 3 Reaction Rate Database.http://www.me.berkeley.edu/gri-mech/

[69] Zuev V S, Kanaev A V and Mikheev L D 1984Sov. J. Quantum Electron. 14135

[70] Bittner J, Kohse-hoinghaus K, Meier U and Just T 1988 Chem. Phys. Lett.143 571

[71] Flower D R and Roueff E 1998J. Phys. B: At. Mol. Opt. Phys.312935

[72] Loureiro J and Ferreira C M 1989J. Phys. D: Appl. Phys.221680

[73] Billing G D and Fisher E R 1976 Chem. Phys.18225

[74] Gorse C, Capitelli M, Bacal M and Bretagne J 1987 Chem. Phys. 117177

[75] Balakrishnan N, Forrey R C and Dalgarno A 1998Phys. Rev. Lett.803224

[76] Wedding A B and Phelps A V 1988J. Chem. Phys.892965

[77] Kligler D J and Rhodes C K 1978 Phys. Rev. Lett.40309 
